\title{
HIBRIDIZAÇ̃̃̃O MAGMÁTICA NO PLÚTON QUIXABA NW DO DOMÍNIO RIO PIRANHAS-SERIDÓ: UM ESTUDO TEXTURAL QUANTITATIVO E QUALITATIVO
}

\author{
Caio de Freitas Tavares ${ }^{1 *}$ \\ Carlos Vinícius Alves Ribeiro ${ }^{1}$ \\ Armando Lucas Souza de Oliveira ${ }^{1}$ \\ Frederico Castro Jobim Vilalva ${ }^{1 ; 2}$ \\ Antonio Carlos Galindo ${ }^{1 ; 2}$ \\ 10.18190/1980-8208/estudosgeologicos.v30n1p3-18 \\ ${ }^{1}$ Departamento de Geologia, CCET UFRN *caiodefreitas@ufrn.edu.br; ${ }^{2}$ Universidade \\ Federal do Rio Grande do Norte, ${ }^{2}$ Programa de Pesquisa e Pós-Graduação em \\ Geodinâmica e Geofísica
}

\section{RESUMO}

O Pluton Quixaba trata-se de uma intrusão de idade ediacarana de dimensões batolíticas, com mais de $100 \mathrm{~km}^{2}$ de área aflorante e orientação NE-SW, localizado no Domínio Rio Piranhas-Seridó (DPS), porção setentrional da Província Borborema. O Plúton apresenta dois fácies, Quixaba e Umari. O fácies Quixaba (predominante) é composto por rochas monzoníticas de textura equigranular muito grossa e coloração rósea. O fácies Umari é composto por rochas dioríticas de textura equigranular e aflora na porção central do corpo, na forma de uma intrusão semi-circular de eixo maior E-W. Essas rochas apresentam dois piroxênios (ferrossilita e diopsídio) e anfibólios subsolidus de composição grunerita e hornblenda. A ocorrência de rochas de composição híbrida nos dois fácies, bem como a presença de enclaves máficos magmáticos, textura tipo rapakivi, quartzo ocelar, morfologias mistas de apatita, synneusis, zonação múltipla e agregados máficos indicam processos de coexistência e mistura local entre os magmas monzoníticos de Quixaba e dioríticos de Umari. A análise textural quantitativa por meio da técnica de distribuição do tamanho dos cristais (CSD) para feldspato potássico das rochas híbridas corroboram esta hipótese e fornecem uma curva de concavidade para cima (típica do processo de mistura de magmas), na qual são identificadas duas populações principais, uma de fenocristais e uma de cristais neoformados..

Palavras chave: Magmatismo ediacarano; Mistura de magmas; CSD; Província Borborema.

\begin{abstract}
The Quixaba Pluton is an Ediacaran age batholith outcropping more than $100 \mathrm{~km}^{2}$ in a NE-SW trend, located within the Rio Piranhas-Seridó Domain (Setentrional portion of the Borborema Province). This pluton is composed by two main facies, Quixaba and Umari. The predominant facies is the Quixaba composed by coarse equigranular pink monzonitic rocks. The Umari facies is composed by the equigranular dioritic rocks in the central part of the Quixaba Pluton as a semi-circular intrusion with main axis E-W trending. This dioritic rocks presents two pyroxenes, ferrossilite and diopside, and subsolidus amphibole of grunerite and hornblende composition. Rocks of hybrid composition between both facies, as well the presence of mafic magmatic enclaves, like rapakivi texture, quartz ocelli, mixed apatites, synneusis and mafic clots indicate coexistence and local mixture processes between the monzonitic magma dioritic magmas.
\end{abstract}


Crystal Size Distribution (CSD) curves for the hydrid rocks corroborate such an interpretation and yield an upward-sloping concave curve (typical of the magma mixing process), that distinguishes two main crystal populations: phenocrystals and neoformed crystals.

Keywords: Ediacaran magmatism; Magma mixing; CSD; Borborema Province

\section{INTRODUÇÃO}

Vários são os trabalhos que tratam do papel de magmas máficos na provisão de calor para a anatexia crustal (Pitcher, 1979; Huppert e Sparks, 1988; Vernon, 1990; Barbarin, 1990; Mariano e Sial, 1990; Neves e Vauchez, 1995; Campos et al., 2002; Hollanda et al., 2003; Barbarin, 2005; Ghaffari, 2015). Esse processo induz a geração de magmas, produzindo um amplo espectro de tipos de rochas, além de morfologias típicas de sua formação (Hibbard, 1991). O magma máfico originado no manto litosférico, durante sua ascensão em direção à crosta, fornece calor suficiente para a fusão parcial das rochas crustais, produzindo magmas félsicos, que se acumulam e, após sucessivas injeções de material máfico, misturam-se, produzindo componentes de composição intermediária (Barker, 1983; Huppert e Sparks, 1988).

A análise dos elementos geométricos em uma rocha ígnea fornece informações significativas da história evolutiva da litosfera, refletida principalmente nas diferentes morfologias encontradas em cada um destes componentes. Evidências diretas do processo de mistura de magmas em magmas silicosos podem ser vistas em diversas texturas e estruturas nas mais variadas escalas (macro, meso e micro), tais como os MME's (enclaves máficos magmáticos), textura tipo rapakivi, clots máficos e quartzo ocelar (Vernon, 1990; Hibbard, 1991; Barbarin, 2005). Além da clássica análise textural, diversos trabalhos (Eberl et al. 1998; Marsh 1988; Higgins 1996, 2000; Morgan e Jerram, 2006; Higgins e Roberge 2007; Brugger e Hammer, 2010; Deb e Bhattacharyya,
2018) vêm tratando da análise textural de rochas a partir de imagens utilizando a técnica de distribuição do tamanho dos cristais (Crystal Size Distribution CSD). Essa técnica tem se mostrado cada vez mais efetiva na compreensão de diversos processos magmáticos, incluindo a mistura de magmas.

O Pluton Quixaba, objeto deste estudo, trata-se uma intrusão bimodal que apresenta de maneira clara a relação entre magmas máficos (fácies Umari) e félsicos (fácies Quixaba), bem como o produto de sua interação. O presente trabalho trata-se de um estudo das feições de hibridização observadas no Pluton Quixaba, baseado na análise dos elementos geométricos (texturas e microtexturas) típicos dos processos de hibridização magmática e distribuição do tamanho dos cristais de K-feldspato. Essas informações permitem compreender os processos de hibridização magmática durante o alojamento do pluton na crosta.

\section{CONTEXTO GEOLÓGICO}

Localizado na porção setentrional da Província Borborema (Figura 1), o Domínio Rio Piranhas-Seridó (DPS) encontra-se delimitado por grandes zonas de cisalhamento transcorrentes, sendo elas, a sul, a Zona de Cisalhamento Patos (ZCP); a leste, a Zona de Cisalhamento Picuí-João Câmara (ZCPJC); e a oeste, a Zona de Cisalhamento Portalegre (ZCPA). A norte encontra-se encoberto pelas rochas sedimentares fanerozoicas da Bacia Potiguar. O DPS é constituído por um embasamento gnássico-migmatítico paleoproterozoico de médio a alto grau, o Complexo Caicó e a Suíte Poço da 
Cruz; por metassupracrustais do Grupo Seridó; e por corpos ígneos intrusivos ediacaranos a cambrianos relacionados a Orogênese Brasiliana (Jardim de Sá, 1994; Van Schmus et al., 2003; Angelim et al., 2006; Souza et al., 2007; Hollanda et al., 2011; Nascimento et al., 2015). Dentro do contexto do magmatismo granítico ediacarano do DPS, está o Pluton Quixaba. Esse corpo encontra-se localizado próximo à cidade de Caraúbas (RN) no Alto Oeste Potiguar (Fig. 1). Trata-se de um corpo alongado de dimensões batolíticas, com mais de 100 $\mathrm{km}^{2}$ de área aflorante e orientação NE-
SW. É intrusivo nos ortognaisses do Complexo Caicó e da Suíte Poço da Cruz e encontra-se recoberto a norte pelas rochas da Bacia Potiguar (Galindo et al., 2008). Os contatos a leste com os Plutons Caraúbas (principalmente) e Umarizal, e a oeste com o Pluton Prado, são delineados pela ZCPA, desenvolvendo localmente protomilonitos nas rochas do plúton Quixaba (Galindo, 1993; Galindo et al. 2017). Análises U-Pb em zircão e Sm-Nd em rocha total no plúton Quixaba forneceram uma idade de $618 \pm 9 \mathrm{Ma}$ para este corpo (Sá et al., 2014).

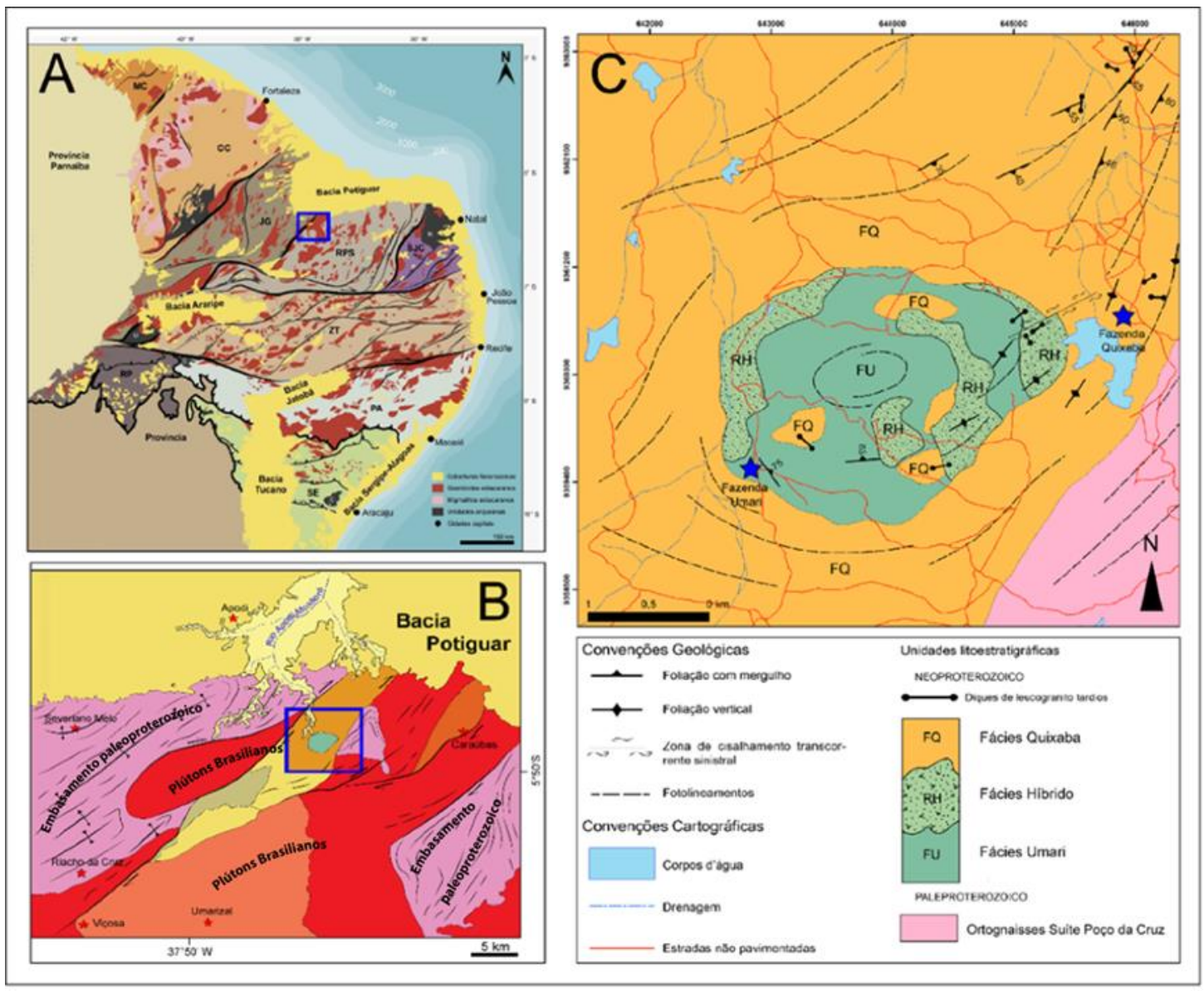

Figura 1: (A) Compartimentação tectônica da Província Borborema, adaptado de Medeiros (2004); (B) Mapa geológico da folha Apodi, adaptado de Galindo et al. (2011); (C) Mapa geológico da área de estudo.

Galindo (1993) define dois fácies para o Granitóide Quixaba a partir de suas características petrográficas e texturais. São eles os fácies Umari (subordinado, de composição máfica Fig. 2A) e Quixaba (dominante, de 
composição félsica - Fig. 2B). O fácies Quixaba corresponde a quartzomonzodioritos, quartzo-monzonitos e monzogranitos subordinados, de coloração rósea, textura equigranular muito grossa, com hornblenda e biotita. O fácies Umari, compreende rochas dioríticas com dois piroxênios e textura equigranular média. Aflora no centro do
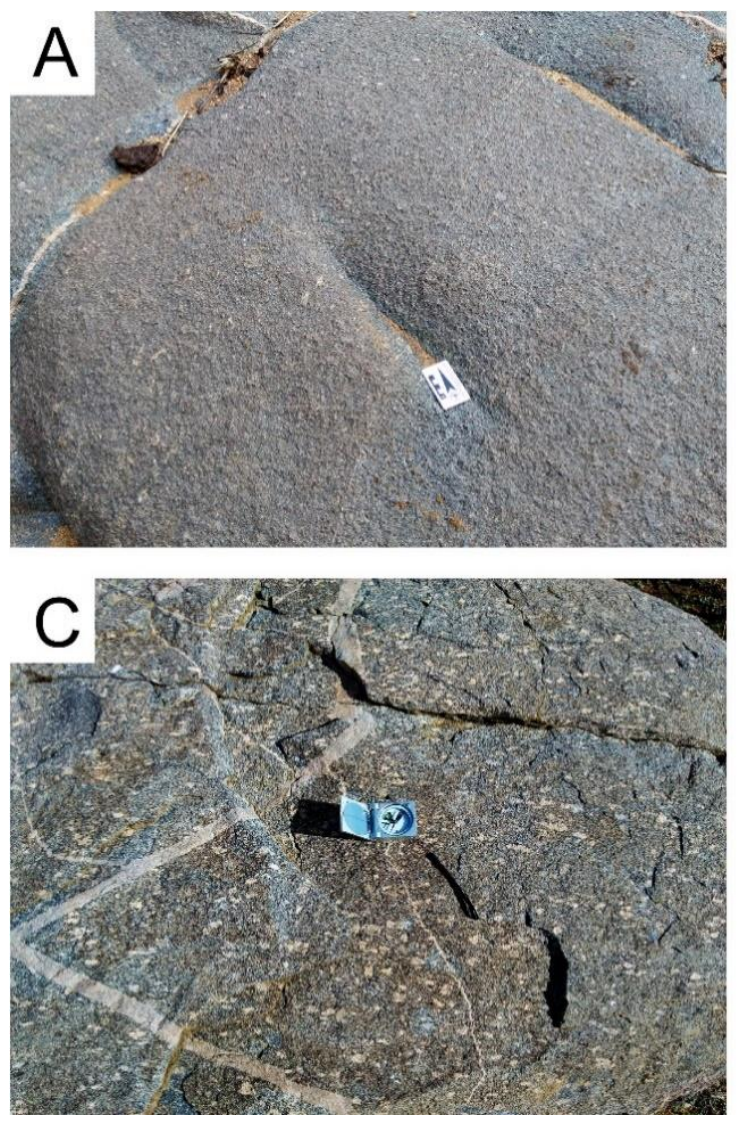

Pluton Quixaba na forma de um corpo semi-circular com eixo maior E-W e cerca de $4 \mathrm{~km}^{2}$ de área aflorante.

Além dos fácies descritos, ocorrem ainda na área de estudo um fácies formado por rochas híbridas (Figs. $2 \mathrm{C} \mathrm{e}$ 2D), diques de leucogranito fino e augen gnaisses monzograníticos da Suíte Poço da Cruz.
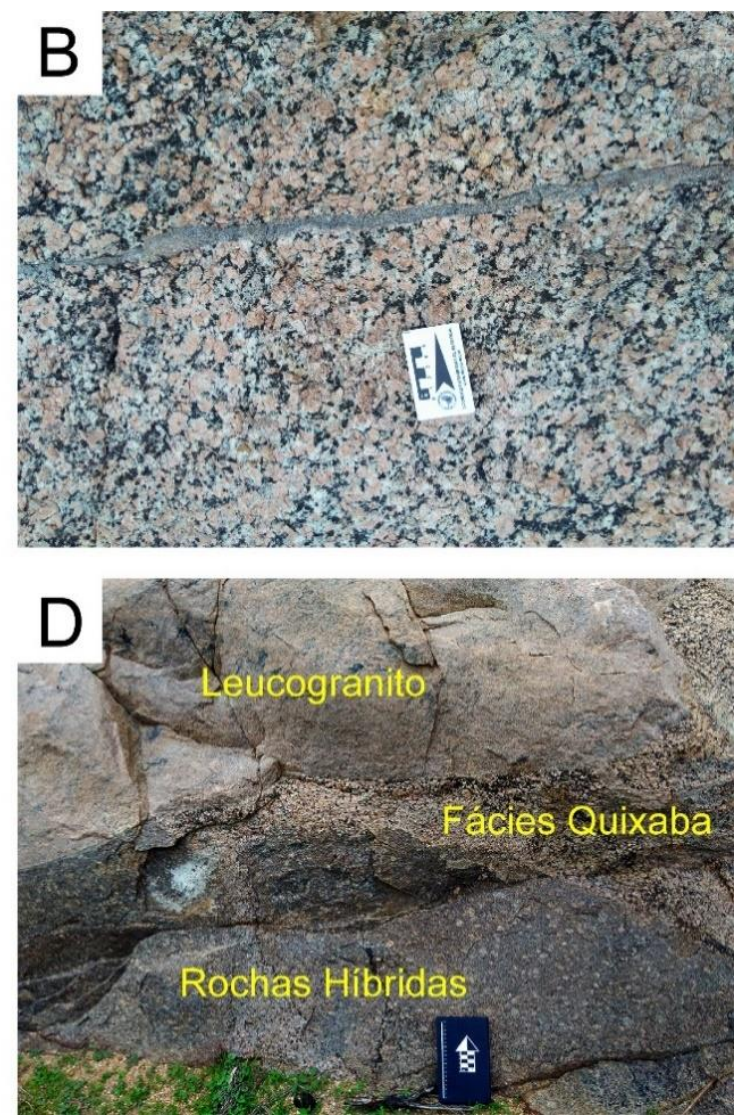

Figura 2: (A) Afloramento do fácies Umari com destaque para suas feições texturais macroscópicas; (B) Afloramento do fácies Quixaba com destaque para suas feições texturais macroscópicas; (C) Afloramento das rochas híbridas onde é possível notar a textura porfirítica com megacristais de K-feldspato; (D) Contato entre as rochas híbridas, o fácies Quixaba e o leucogranito.

\section{MATERIAIS E MÉTODOS}

Para a realização do estudo e caracterização petrográfica foram confeccionadas 12 seções delgadas. O reconhecimento da abundância aproximada dos minerais nessas rochas foi estabelecido a partir de análise semiquantitativa por simples visão das seções delgadas baseando-se em estimativas visuais de dez campos por lâmina, conforme a metodologia empregada por Motoki (2004) e Pinho Neto et al. (2019). Foram selecionadas 6 amostras para análise da distribuição do tamanho dos cristais (CSD) de K- 
feldspato. Esse mineral foi escolhido por se tratar de uma fase mineral que registra bem a mistura entre os dois magmas, visto que é o feldspato predominante no fácies Quixaba e escasso no fácies Umari $(<2 \%$ em volume total). As amostras foram preparadas no Laboratório de Geoquímica da UFRN, onde foram atacadas com ácido fluorídrico $40 \%$ e posteriormente tratadas com uma solução de cobalto-nitrito de sódio a uma concentração de $300 \mathrm{~g} / \mathrm{L}$. Esse reagente é usado em testes qualitativos para íons potássio e amônio, causando o tingimento na cor amarela dos cristais de feldspato potássico, permitindo assim distingui-los dos cristais de quartzo e plagioclásio.

Após essa etapa, cada amostra foi digitalizada em impressora digital de alta resolução (2400 dpi) para posterior tratamento de imagens. As imagens obtidas (Fig. 3) foram convertidas em imagens binárias utilizando o software Adobe Photoshop CC 2018. A área total medida de cada amostra, bem como os eixos maiores e menores das elipses correspondentes a cada cristal foram calculados a partir do software ImageJ. Como o método CSD utiliza-se de medidas volumétricas e as amostras utilizadas são seções em duas dimensões, foi necessário fazer o modelamento dos dados em três dimensões. Para isso, foi utilizado o software CSDCorrections 1.6 (Higgins, 2000) na projeção e correção dos efeitos de corte da seção.

A utilização desse software (CSDCorresctions 1.6) requer a estimativa de alguns parâmetros geométricos dos cristais, tais como o fabric da rocha, o grau de arredondamento dos cristais e a presença ou não de vesículas. A forma dos cristais em três dimensões foi estimada utilizando-se o software CSDslice 5 (Morgan e Jerram, 2006). Esse software faz uso de um banco de dados que compara as curvas obtidas das medidas em duas dimensões da amostra com curvas de 703 diferentes hábitos cristalinos. Os parâmetros geométricos de cada amostra obtidos após a etapa de processamento das imagens podem ser observados na Tabela 1.
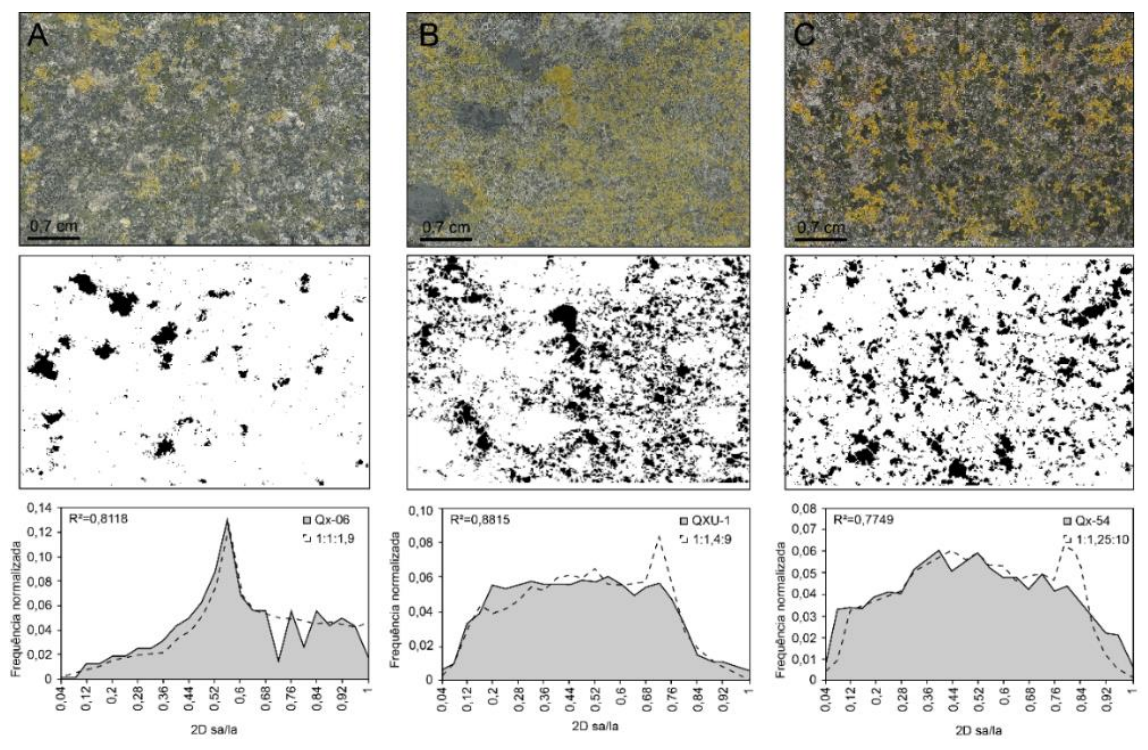

Figura 3: Imagens obtidas do escaneamento das amostras tingidas (A); imagens binárias adquiridas após o processamento digital (B); e curvas de correlação entre os dados reais (tracejado) e modelos teóricos (em cinza) para as formas tridimensionais dos cristais de feldspato potássico (C). 


\section{PETROGRAFIA}

Foram estudadas duas amostras de diorito do fácies Umari, sendo as demais correspondentes às rochas híbridas (quartzo-monzonitos, quartzo-monzo- dioritos e monzodioritos) produtos dos diferentes graus de mistura entre Umari e Quixaba. Os resultados das análises modais das 12 seções delgadas foram lançados nos diagramas Q-A-P e Q(A+P)-M' (Streckeisen, 1976; Fig. 4).

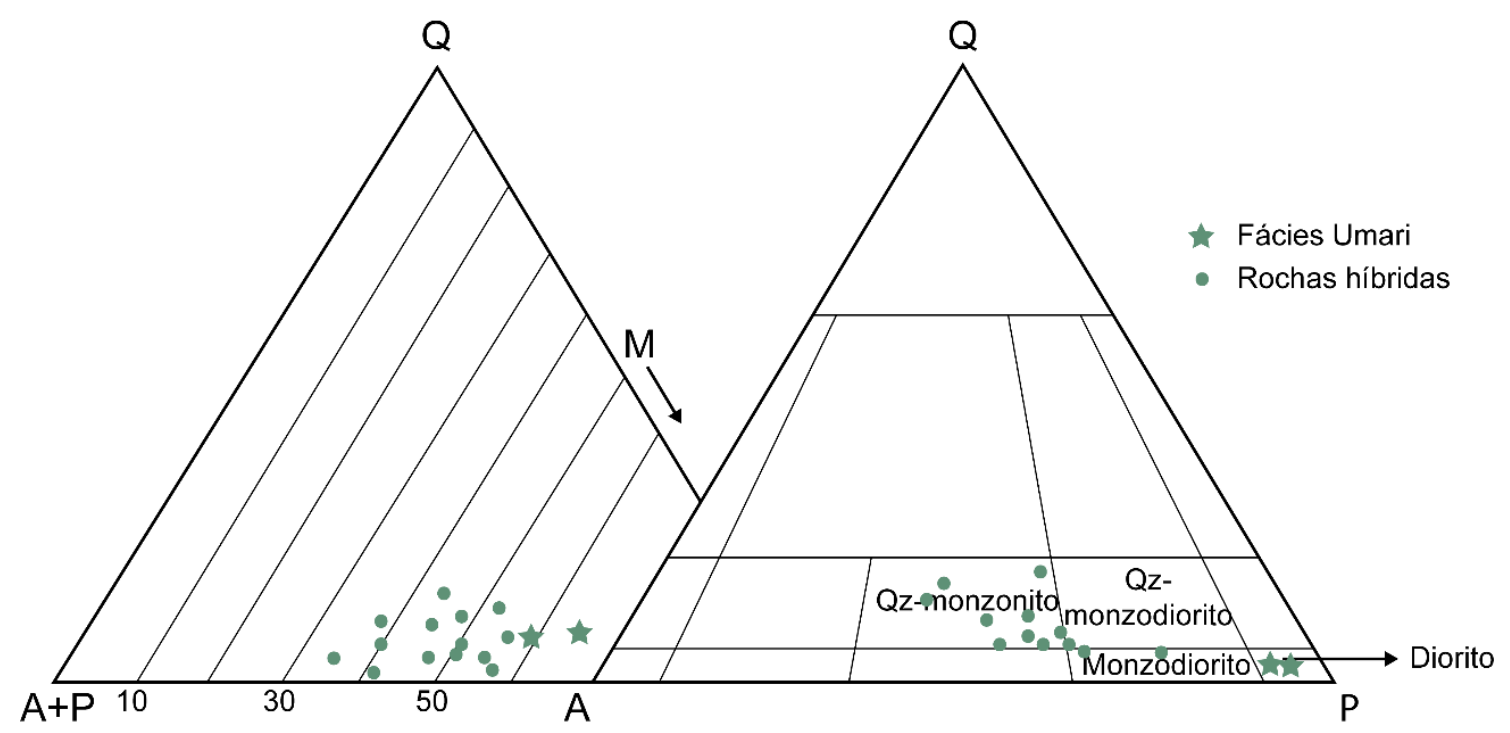

Figura 4: Diagrama QAP e Q(A+P)M (Streckeisen, 1976) para classificação das

Tabela 1: Parâmetros geométricos das amostras das rochas híbridas utilizados no cálculo do CSD. Os valores obtidos (Fig. 3) apresentam boa confiabilidade, visto que o valor mínimo para a determinação robusta do hábito dos cristais é de 75 seções para cristais tabulares (Qx-06 e Qx-46) e 250 para cristais aciculares (Q-1, Qx-40b, Qx-54 e QXU-1; Morgan e Jerram, 2006).

\begin{tabular}{|c|c|c|c|c|c|c|c|c|c|}
\hline \multirow[t]{2}{*}{$\begin{array}{l}\mathrm{N}^{\circ} \mathrm{da} \\
\text { amostra }\end{array}$} & \multirow[t]{2}{*}{$\begin{array}{l}\mathrm{N}^{\circ} \text { de } \\
\text { cristais }\end{array}$} & \multirow{2}{*}{$\begin{array}{c}\text { Area } \\
\text { medida } \\
(\mathrm{mm})\end{array}$} & \multirow{2}{*}{$\begin{array}{c}\text { Proporçảo } \\
\text { volumétrica } \\
\%\end{array}$} & \multicolumn{3}{|c|}{$\begin{array}{c}\text { Razão axial 3D (CSD } \\
\text { slice) }\end{array}$} & \multirow{2}{*}{$\begin{array}{c}\mathrm{R}^{2} \\
\text { ideal } \\
\text { (CSD } \\
\text { slice) }\end{array}$} & \multirow[t]{2}{*}{ Fabric } & \multirow{2}{*}{$\begin{array}{c}\text { Arredondamento } \\
\text { 0 a } 1\end{array}$} \\
\hline & & & & $x$ & $\mathbf{Y}$ & $\bar{z}$ & & & \\
\hline Q-1 & 858 & 2880,34 & 14,90 & 1,00 & 1,90 & 8,00 & 0,7361 & Acicular & 0,5 \\
\hline$Q x-06$ & 169 & 2469,15 & 8,11 & 1,00 & 1,00 & 1,90 & 0,8118 & Tabular & 0,4 \\
\hline$Q x-40 b$ & 909 & 2123,49 & 23,00 & 1,00 & 1,60 & 10,00 & 0,8054 & Acicular & 0,5 \\
\hline$Q \times-46$ & 141 & 3666,49 & 3,33 & 1,00 & 1,05 & 2,90 & 0,6006 & Acicular & 0,4 \\
\hline Qx-54 & 1091 & 2240,58 & 53,9 & 1,00 & 1,25 & 10,00 & 0,7749 & Acicular & 0,4 \\
\hline QXU-1 & 2429 & 2659,96 & 33,9 & 1,00 & 1,40 & 9,00 & 0,8815 & Acicular & 0,4 \\
\hline
\end{tabular}




\section{Fácies Umari}

As rochas do fácies Umari são compostas por plagioclásio, K-feldspato, quartzo, ferrossilita, diopsídio, hornblenda, grunerita, biotita, apatita e zircão. Os cristais de plagioclásio são euédricos, prismáticos, alongados, com tamanho entre 0,5 e $1,0 \mathrm{~mm}$. Os cristais de K-feldspato são subédricos a anédricos, apresentam pertitas e tamanho entre 0,3 e $0,7 \mathrm{~mm}$. Os cristais de quartzo são anédricos, com tamanho inferior a $0,5 \mathrm{~mm}$ e apresentam com frequência extinção ondulante. Os cristais de ferrossilita são anédricos,com cerca de 0,9 mm (Figs. 5A e 5B). Apresentam-se envoltos por uma coroa fina e irregular de grunerita, sobrecrescida por hornblenda. Já os cristais de diopsídio são prismáticos, com tamanho entre 0,8 e 3,0 mm (Fig. 5C). Esse mineral tem frequentemente suas bordas corroídas, formando simplectitos de hornblenda + quartzo). A biotita é lamelar, com cerca de $0,8 \mathrm{~mm}$, enquanto a hornblenda prismática tem tamanho médio de 0,9 $\mathrm{mm}$.

\section{Rochas Híbridas}

Modalmente, as rochas híbridas correspondem a quartzo-monzonitos, quartzo-monzodioritos e monzodioritos (Fig. 4) com 2 assembleias máficas: ferrossilita-diopsídio e biotitahornblenda. Essas rochas afloram próximas aos contatos entre os fácies Quixaba e Umari. A assembleia com ferrossilita-diopsídio é composta por cristais subédricos de plagioclásio (menos alongados que os plagioclásios dos dioritos, com cerca de $2 \mathrm{~mm}$ ), cristais anédricos de quartzo, $\mathrm{K}$ feldspato (entre $2 \mathrm{~mm}$ e $2 \mathrm{~cm}$ ), hornblenda, e cristais lamelares de biotita. Os cristais de ferrossilita e dipsídio apresentam bordas de reação formando grunerita + hornblenda (Fig. 5D) e hornblenda + quartzo (Fig. 5E), respectivamente. $\mathrm{Na}$ biotita é possível notar dobras com geometria semelhante a kink bands (Fig. 5F).

As amostras com a assembleia máfica hornblenda-biotita apresentam características texturais e morfológicas semelhantes à assembleia ferrossilitadiopsídio. Nessas amostras foi observado sobrecrescimento de titanita na forma de coronas em minerais opacos, formadas pelo processo de esfenitização (Fig. 5G), cristais zonados de allanita e cristais prismáticos bem desenvolvidos (menores que $0,5 \mathrm{~mm}$ ) de apatita. A presença destes minerais denota um caráter mais evoluído para essas rochas em termos de composição química e fugacidade de oxigênio. Mirmequitas (Fig. 5H), carbonatos e mica branca ocorrem como fases secundárias ligadas às transformações tardi a pósmagmáticas.

Com base na estabilidade da assembleia ferrossilita-diopsídio, a cristalização dessa rocha começou a temperaturas de liquidus da ordem de $850-900^{\circ} \mathrm{C}$. Com o avanço da cristalização, em função da ascensão do corpo, atingiu-se temperaturas da ordem de $750^{\circ} \mathrm{C}$, registrado na associação clinopiroxênio-hornblenda. A etapa final de cristalização se deu a temperaturas da ordem de $700^{\circ} \mathrm{C}$ e pressões de cerca de 6-7 kbar. A presença de grunerita como fase de substituição da ferrossilita registra o arrefecimento em condições de subsolidus. Os valores mínimos de temperatura e pressão que marcam a estabilidade da passagem de uma fase para a outra são por volta de $560^{\circ} \mathrm{C}$ e 2,3 kbar (Myiano e Klein, 1983; Tetsopgang e Enami, 2003). 

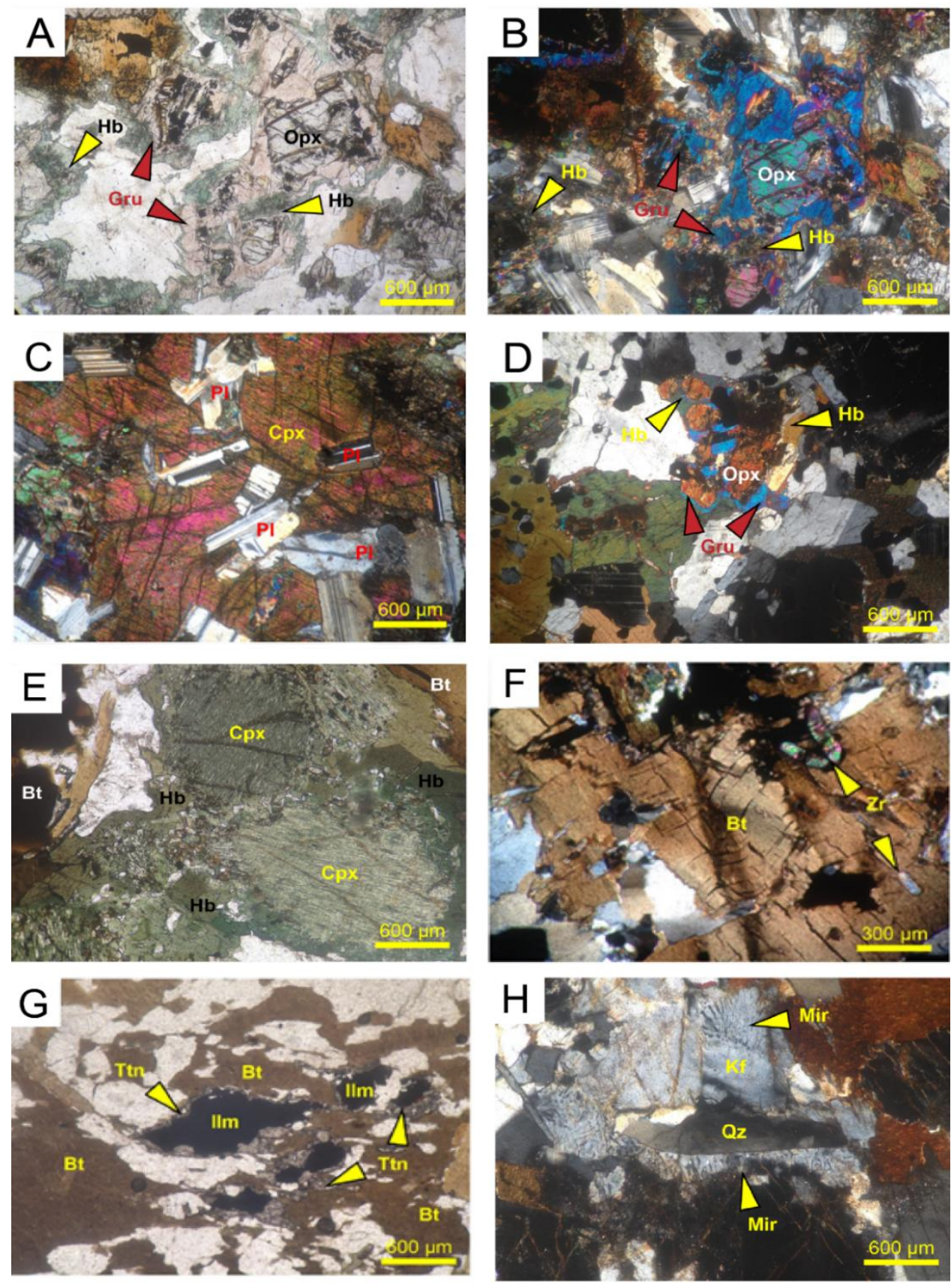

Figura 5: (A) e (B) Fotomicrografias a filtros polarizadores paralelos e cruzados destacando corona dupla de grunerita + hornblenda em torno de ferrosssilita no fácies Umari; (C) Fotomicrografia a filtros polarizadores cruzados de textura ofítica observada em cristais de diopsídio envolvendo cristais prismáticos alongados de plagioclásio; (D) Fotomicrografia a filtros polarizadores paralelos da textura em corona dupla de grunerita + hornblenda em amostra das rochas híbridas; (E) Fotomicrografia a filtros polarizadores paralelos de simplectitos de hornblenda+quartzo a partir da desestabilização de diopsídio; (F) Fotomicrografia a filtros polarizadores paralelos de cristal de biotita com kink bands e inclusões de apatita e zircão apatita e zircão; $(G)$ Fotomicrografia a filtros polarizadores paralelos destacando o sobrecrescimento de titanita em ilmenita; $(\mathrm{H})$ Fotomicrografia a filtros polarizadores cruzados de cristais de $\mathrm{K}$-feldspato destacando a presença de mirmequitas bulbosas (seta amarela). Abreviações minerais: $\mathrm{Hb}=$ hornblenda, Gru= grunerita, $\mathrm{Opx}=$ ortopiroxênio, $\mathrm{Cpx}=$ clinopiroxênio, $\mathrm{Pl}=$ plagioclásio, $\mathrm{Bt}=$ biotita, $\mathrm{Zr}=$ zircão, $\mathrm{Ttn}=$ titanita, Ilm=ilmenita, $\mathrm{Kf}=\mathrm{K}$-feldspato, Qz=quartzo, Mir=mirmequita. 
Esses dados fornecem uma taxa de descompressão de aproximadamente 1 $\mathrm{kbar} / 40^{\circ} \mathrm{C}$ e sugerem que o Pluton Quixaba residiu durante um longo período de tempo na crosta média durante seu arrefecimento. Corpos com mineralogia e estimativas de pressão e temperatura semelhantes foram estudados tanto na Província Borborema (Sial, 1989; Galindo, 1993), quanto na sua contra-parte no Cinturão PanAfricano na Nigéria e no Camarões (Ferré et al., 1997; Tetsopgang e Enami, 2003).

\section{ANÁLISE TEXTURAL QUALITATIVA}

Em diversos afloramentos do fácies Quixaba foram observados MME's (Figura 6A). Os enclaves possuem dimensões decimétricas (entre 10 e $25 \mathrm{~cm}$ ) com a presença de cristais de K-feldspato com bordas de cristalização, forma alongada e contatos ora bem marcados, ora difusos (Fig. 6B). Esses enclaves formam cumulados cristalinos com forma de bolha, indicando a coexistência de dois magmas, sendo um deles mais máfico e quente que o outro, seu hospedeiro (Didier e Barbarin, 1991; Johnston, 2001; Barbarin, 2005; Kumar, 2010; Hodge e Jellinek 2012).

Nas rochas híbridas foram observados cristais de K-feldspato com a textura tipo rapakivi (Figura 6C). Os cristais apresentam cerca de $3 \mathrm{~cm}$, coloração rósea, formato ovalado e uma camada com cerca de $0,5 \mathrm{~cm}$ de albita que envolve o cristal. Quando ocorre a mistura entre magmas, cristais de $\mathrm{K}$ feldspato derivados do sistema félsico (Quixaba) podem ser inseridos no sistema máfico (Umari) e serem parcialmente dissolvidos e, posteriormente, envolvidos por albita (mais saturada nesse ambiente). Desta forma, cristaliza-se uma borda de albita sobre a superfície dos cristais de $\mathrm{K}$ feldspato formando a textura tipo rapakivi (Vernon, 1990, 1991; Hibbard, 1991).

Nessas rochas há ainda cristais de quartzo com a textura ocelar (Fig. 6D). São cristais com formato globular com cerca de $1 \mathrm{~cm}$, envoltos por uma camada de cristais de anfibólio com cerca de 0,25 $\mathrm{cm}$. Essa textura ocorre quando alguns fenocristais de quartzo (predominantes no sistema félsico) acabam sendo introduzidos em um magma híbrido, passando a uma condição termodinamicamente instável. Nesse ambiente ocorre a extração de calor latente da superfície dos seus cristais, causando um subarrefecimento que induz a cristalização de anfibólio no seu entorno (Vernon, 1990, 1991; Hibbard, 1991; Baxter e Feely, 2002). A presença da textura tipo rapakivi e quartzo ocelar representam processos mineralógicos que registram macroscopicamente os efeitos do processo de hibridização magmática.

Em microescala as amostras do fácies Umari apresentam textura ofítica, com oicocristais de clinopiroxênio com mais de $4 \mathrm{~mm}$ e chadacristais de plagioclásio. Essa feição é característica de rochas máficas. Nas amostras das rochas híbridas, em relação aos feldspatos, é comum observar cristais de plagioclásio prismáticos com zonação múltipla e synneusis (Figs. 6E e 6F). Além disso, são observadas morfologias mistas de apatita (mixed apatites - Fig. 6G) e agregados máficos (mafic clots Fig. 6H). A coexistência de duas morfologias de apatita, acicular e prismática, bem como a zonação múltipla e synneusis nos plagioclásios, podem ser explicados a partir da mistura de magmas. 

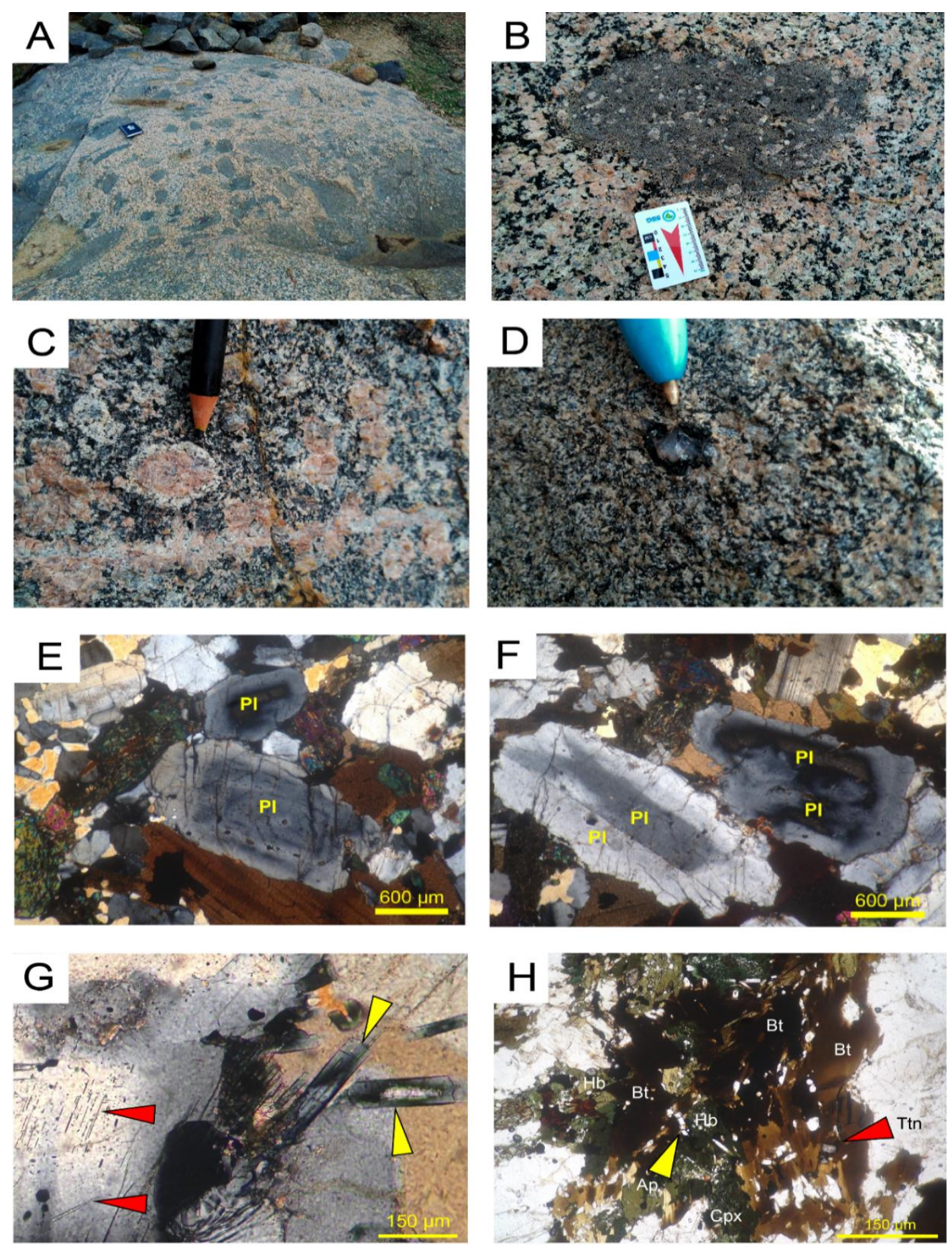

Figura 6: (A) Enxame de enclaves máficos no contato entre os dois fácies; (B) Detalhe de enclave máfico com cristais de K-feldspato capturados mecanicamente; (C) Cristal de K-feldspato com textura tipo rapakivi nas rochas híbridas; (D) Textura ocelar observada nas rochas híbridas; (E) Fotomicrografias a filtros polarizadores cruzados de cristais de plagioclásio $(\mathrm{Pl})$ apresentando zonação múltipla; (F) Fotomicrografias a filtros polarizadores cruzados de cristais de plagioclásio apresentando synneusis; (G) Fotomicrografia a filtros polarizadores cruzados destacando duas morfologias de apatita, acicular (seta vermelha) e prismática (seta amarela); (H) Agregado máfico composto por hornblenda, biotita e apatita com destaque para cristal de titanita (seta vermelha) e apatita (seta amarela). Abreviações minerais: $\mathrm{Hb}=$ hornblenda, $\mathrm{Cpx}=$ clinopiroxênio, $\mathrm{Pl}=$ plagioclásio, $\mathrm{Bt}=$ biotita. 
Em relação à apatita, os cristais aciculares são interpretados como formados por arrefecimento rápido (quenching) do material máfico quando incorporado a uma hospedeira félsica, que guarda os cristais prismáticos de apatita (Hibbard, 1991; Baxter e Feely, 2002). A presença de zonação múltipla indica variações bruscas nas condições dinâmicas de cristalização e, consequentemente, na composição e nas taxas de crescimento dos cristais, sendo um ótimo registro das variações termodinâmicas durante a mistura de magmas (Nixon e Pearce, 1987; Barbarin, 1990). Já a formação de synneusis é devida ao processo de fixação ou união de cristais em suspensão no magma e consequente sobrecrescimento de plagioclásio envolvendo o grupo como um todo. Esse processo geralmente ocorre em estágios precoces de cristalização magmática, sendo necessário um magma fluido o suficiente para movimentar os cristais (Vance, 1969). A presença dessa microtextura indica o crescimento dos cristais de plagioclásio ocorrido em um ambiente de magmas de baixa viscosidade com pulsos de turbulência magmática.

\section{ANÁLISE TEXTURAL QUANTITATIVA(CSD)}

Uma ampla gama de processos e condições podem afetar o tamanho dos cristais e sua distribuição nas rochas. $\mathrm{O}$ método CSD baseia-se nas taxas de crescimento e nucleação dos cristais durante a história de cristalização de uma rocha ígnea. No diagrama de distribuição do tamanho dos cristais, o logaritmo natural (Ln) da densidade de população dos cristais é plotado em relação ao tamanho dos mesmos (Higgins, 2000). Higgins (1996) alerta para o fato de que quando ocorre mistura entre dois magmas, este modelo de uma única população de cristais não pode ser aplicado. Desta forma, a mistura representa duas populações de cristais, cada qual devendo ser analisada separadamente. Assim, os gráficos apresentam a feição característica de uma curva com concavidade para cima (Fig. 7), resultado da união de duas retas com diferentes inclinações (Marsh, 1988; Higgins, 2000). Esse padrão diz respeito a duas populações distintas de cristais, uma delas correspondente a poucos cristais com dimensões mais desenvolvidas e a outra a muitos cristais diminutos. Os cristais de feldspato potássico maiores são interpretados como cristais capturados e preservados durante a interação entre os dois componentes magmáticos (aqui tratados de fenocristais). Tratam-se de cristais tabulares, com tamanho entre $2 \mathrm{~mm}$ e 2 $\mathrm{cm}$, apresentando tanto macro, quanto microscopicamente, bordas irregulares e contatos lobados, o que é indicativo de processos de absorção pelo magma. 

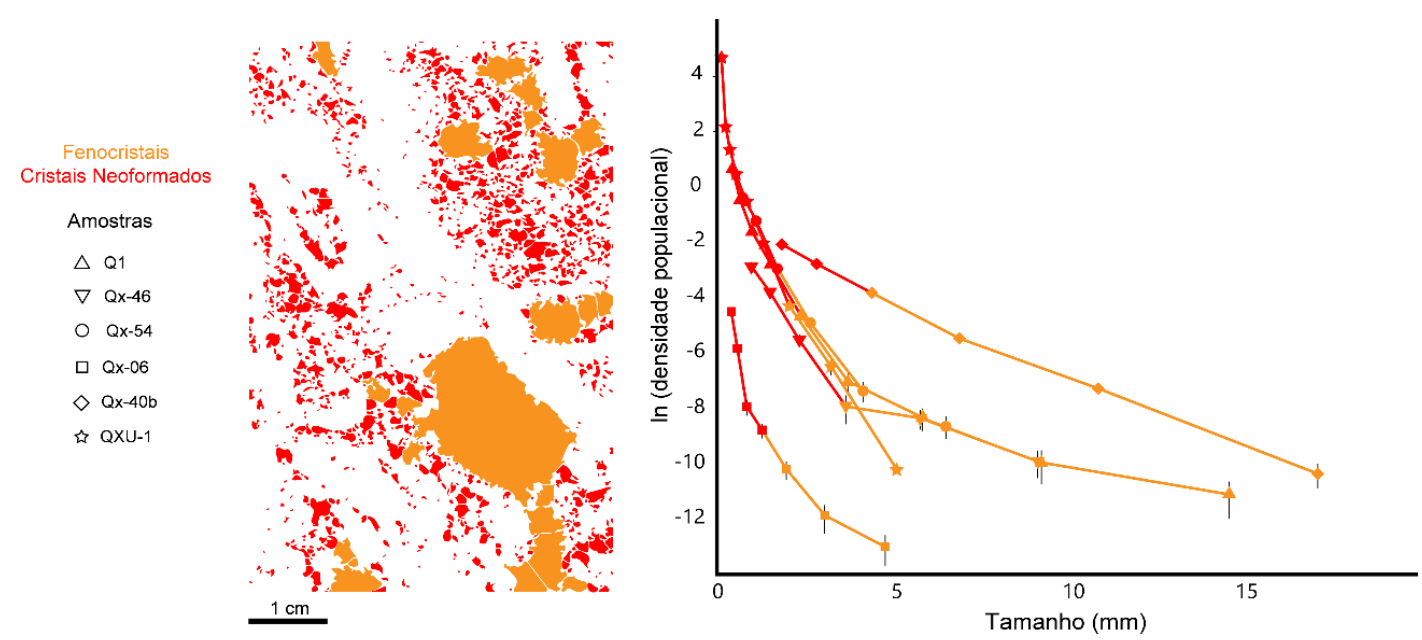

Figura 7: Curvas CSD para as amostras analisadas das rochas híbridas do Pluton Quixaba com o padrão com concavidade para cima. Em destaque à esquerda, estão assinalados os cristais fenocristais (vermelho) e cristais neoformados (laranja) considerados no cálculo das curvas CSD.

A outra população trata-se de cristais menores que $1,0 \mathrm{~mm}$, de hábito prismático a acicular e que se encontram em maior proporção nas amostras. Essa população foi interpretada como uma população neoformada durante a interação entre os magmas tendo sido cristalizada por arrefecimento brusco devido a interação entre dois líquidos magmáticos com contraste de temperatura.

Foram calculados os tempos de residência de cada população de cristais de feldspato potássico das amostras utilizando o método de regressão linear da reta em que o valor da inclinação é dado por $-1 / \mathrm{Gt}$ sendo $\mathrm{G}$ a taxa de nucleação do mineral analisado e $\mathrm{t} o$ tempo de residência. Utilizou-se o valor $1 \times 10^{-10} \mathrm{~ms}^{-1}$ para as taxas de crescimento dos cristais de feldspato potássico em cristalização eutética com quartzo em um sistema hidratado (Barker e Freda, 2001). Os valores obtidos para os cristais neoformados variaram entre 113 e 450 anos, porém, por serem rochas ígneas plutônicas as quais os processos magmáticos são da ordem de milhares a milhões de anos, esses valores não possuem significado geológico aparente.

\section{CONCLUSÕES}

A coexistência de magmas na crosta pode levar a processos de hibridização (mixing e mingling) dependendo dos contrastes de densidade, viscosidade e composição química entre os mesmos (Didier e Barbarin, 1991; Barbarin, 2005; Kumar, 2010, Hodge e Jellinek 2012). Como resultado, é formada uma variedade de feições típicas deste processo, seja em escala de afloramento ou microscópica (Vernon 1990, 1991; Hibbard 1991; Baxter e Feely 2002). A produção de rochas híbridas das mais diversas composições (quartzo-monzodioritos, monzodioritos e quartzo-monzonitos) bem como os valores de pressão e temperatura obtidos para ambos os fácies confirmam a existência de magmas de diferentes fontes e a hibridização magmática como processo dominante durante $o$ alojamento do Pluton Quixaba na crosta. Esse processo é registrado nas diferentes 
texturas observadas em escala macro, meso e microscópica. As inferências de pressão e temperatura obtidas a partir da presença de grunerita como fase tardia sugerem um arrefecimento lento em condições de crosta média.

A análise textural quantitativa por meio da técnica da distribuição do tamanho dos cristais (CSD) viabilizou fazer um modelamento próximo ao real das diferentes morfologias dos cristais de feldspato potássico das rochas híbridas do Pluton Quixaba. Os padrões obtidos pelas curvas de CSD (a presença de poucos fenocristais e muitos cristais neoformados) confirmam estatisticamente os processos de interação entre magma félsico e um magma máfico e geração de rochas híbridas

Estudos quantitativos (análises químicas de rocha total, isótopos $\mathrm{e}$ química mineral) desse fenômeno permitem caracterizar de maneira mais precisa alguns dos processos geradores dessas rochas. Recomenda-se em trabalhos futuros a caracterização litoquímica do fácies Umari com o objetivo de definir sua filiação magmática, além de estimativas mais precisas das condições de cristalização $\left(\mathrm{P}, \mathrm{T}\right.$ e $\left.f \mathrm{O}_{2}\right)$ relativas a evolução, cristalização e alojamento do magma.

\section{AGRADECIMENTOS}

Agradecimentos ao técnico do Laboratório de Laminação do Departamento de Geologia da UFRN Geólogo Emanoel Maria de Morais e à professora Dr. Raquel Franco de Souza pelo suporte instrumental à pesquisa. Agradecimentos também à professora Dr. Ignez de Pinho Guimarães pelas sugestões e correções que engrandeceram o trabalho.

\section{REFERÊNCIAS}

ANGELIM, L. A. A.; MEDEIROS, V. C.; NESI, J. R. (2006). Geologia e recursos minerais do estado do Rio Grande do Norte - Escala 1:500.000. Mapa e texto explicativo. CPRM-Serviço Geológico do Brasil, 119 p.

BARBARIN, B. (1990). Plagioclase xenocrysts and mafic magmatic enclaves in some granitoids of the Sierra Nevada Batholith, California. Journal of Geophysical Research: Solid Earth, v. 95, n. B11, p. 1774717756.

BARBARIN, B. (2005). Mafic magmatic enclaves and mafic rocks associated with some granitoids of the central Sierra Nevada batholith, California: nature, origin, and relations with the hosts. Lithos, v. 80, n. 1-4, p. 155-177.

BARKER, D. S. (1983). Igneous rocks. Prentice Hall.

BAKER, D. R.; FREDA, C. (2001). Eutectic crystallization in the undercooled Orthoclase-Quartz$\mathrm{H} 2 \mathrm{O}$ system experiments and simulations. European Journal of Mineralogy, v. 13, n. 3, p. 453466.

BAXTER, S.; FEELY, M.; (2002). Magma mixing and mingling textures in granitoids: examples from the Galway Granite, Connemara, Ireland. Mineralogy and Petrology, v. 76, n. 1-2, p. 6374.

BRUGGER, C. R.; HAMMER, J. E. (2010). Crystal size distribution analysis of plagioclase in experimentally decompressed hydrous rhyodacite magma. Earth and Planetary Science Letters, v. 300, n. 3-4, p. 246-254.

CAMPOS, T. F. C.; NEIVA, A. M. R.; NARDI, L. V. S.; (2002). Geochemistry of the Rio Espinharas hybrid complex, 
northeastern Brazil. Lithos, v. 64, n. 3-4, p. 131-153.

DEB, T; BHATTACHARYYA, T. (2018). Interaction between felsic granitoids and mafic dykes in Bundelkhand Craton: A field, petrographic and crystal size distribution study. Journal of Earth System Science, v. 127, n. 7, p. 102.

DIDIER J, BARBARIN, B.; (1991). Enclaves and granite petrology. Elsevier, Amsterdam, p. 549.

EBERL, D. D.; DRITS, V. A.; SRODON, J. (1998). Deducing growth mechanisms for minerals from the shapes of crystal size distributions. American Journal of Science, v. 298, n. 6, p. 499533.

FERRÉ, E. C., CABY, R., PEUCAT, J. J., CAPDEVILA, R., MONIÉ, P. (1998). Pan-African, postcollisional, ferro-potassic granite and quartz-monzonite plutons of Eastern Nigeria. Lithos, 45(1-4), 255-279.

GALINDO, A. C. (1993). Petrologia dos granitóides brasilianos da região de Caraúbas - Umarizal, Oeste do Rio Grande do Norte. Tese de Doutorado, CG-UFPA. $370 \mathrm{p}$.

GALINDO, A.C., MAIA, H.N., SOUZA, L.C., SRIVASTAVA, N.K., FILLIPPI, R.R., OLIVEIRA, M.T.D., ARAÚJO, A.G.S. (2017). Geologia e Recursos Minerais da Folha Apodi, SB.24-X-C-VI. Nota Explicativa, CPRM-Serviço Geológico do Brasil.

GHAFFARI, M.; RASHIDNEJADOMRAN, N. (2015). Magma mixing/mingling in Salmas granodiorite, NW Iran: Evidence from mafic microgranular enclaves. Arabian Journal of Geosciences, v. 8, n. 9, p. 71417152 .
HODGE, K. F.; JELLINEK, A. M. (2012). Linking enclave formation to magma rheology. Journal of Geophysical Research: Solid Earth, v. 117, n. B10.

HOLLANDA, M. H. B., ARCHANJO, C. J., SOUZA, L. C., DUNYI, L., ARMSTRONG, R. (2011). Longlived Paleoproterozoic granitic magmatism in the SeridóJaguaribe domain, Borborema Province-NE Brazil. Journal of South American Earth Sciences, 32(4), 287-300.

HOLLANDA, M. H. B. M.; PIMENTEL, M. M.; JARDIM DE SÁ, E. F. (2003). Paleoproterozoic subduction-related metasomatic signatures in the lithospheric mantle beneath NE Brazil: inferences from trace element and $\mathrm{Sr}-\mathrm{Nd}-\mathrm{Pb}$ isotopic compositions of Neoproterozoic high-K igneous rocks. Journal of South American Earth Sciences, v. 15, n. 8, p. 885900.

HIBBARD, M.J. (1991). Textural anatomy of twelve magma-mixed granitoid systems. In: Didier, J., Barbarin, B. (Eds.), Enclaves and Granite Petrology. Elsevier, Amsterdam, pp. 431-444.

HIGGINS, M. D. (1996). Crystal size distributions and other quantitative textural measurements in lavas and tuff from Mt. Taranaki (Egmont volcano), New Zealand; Bull. Volcanol. 58 194-204.

HIGGINS, M.D. (2000). Measurement of Crystal Size Distributions. American Mineralogist, 85, 11051116.

HIGGINS, M D; ROBERGE, J. (2007). Three magmatic components in the 1973 eruption of Eldfell volcano, Iceland: Evidence from plagioclase crystal size distribution (CSD) and geochemistry; J. Volcanol. Geotherm. Res. 161(3) 247-260. 
HUPPERT, H. E.; SPARKS, R. S. J. (1988). The generation of granitic magmas by intrusion of basalt into continental crust. Journal of Petrology, v. 29, n. 3, p. 599-624.

JARDIM DE SÁ, E.F. (1994). A Faixa Seridó (Província Borborema, NE do Brasil) e o seu significado geodinâmico na Cadeia Brasiliana/PanAfricana.

Brasília. (Tese de Doutorado) Instituto de Geociências da Universidade de Brasília, Brasília. P. 804.

JOHNSTON, B.; (2001). Magmatic Enclaves and Evidence for Magma Mixing in the Oak Point Granite, Deer Isle, Maine, USA.

KUMAR, S.; (2010). Mafic to hybrid microgranular enclaves in the Ladakh batholith, northwest Himalaya: Implications on calcalkaline magma chamber processes. Journal of the Geological Society of India, v. 76, n. 1, p. $5-25 \mathrm{ku}$.

MARIANO, Gorki; SIAL, Alcides Nóbrega. Coexistence and mixing of magmas in the Late Precambrian Itaporanga batholith, state of Paraíba, northeastern Brazil. Revista Brasileira de Geociências, v. 20, n. 1-4, p. 101110, 1990.

MARSH, B. D. (1988). Crystal size distribution (CSD) in rocks and the kinetics and dynamics of crystallization I Theory; Contrib. Mineral. Petrol. 99 277-291.

MEDEIROS, V. C. (2004). Evolução geodinâmica e condicionamento estrutural dos terrenos PiancóAlto Brígida e Alto Pajeú, Domínio da Zona Transversal, NE do Brasil. Tese de Doutorado. Tese de Doutourado. PPGG/UFRN, Natal.

MORGAN, D. J.; JERRAM, D. A. (2006). On estimating crystal shape for crystal size distribution analysis. Journal of Volcanology and Geothermal Research, v. 154, n. 1-2, p. 1-7.

MOTOKI, A.; (2004). Descrição petrográfica de rochas ígneas. Departamento de Mineralogia e Petrologia Ígnea da Universidade do Estado do Rio de Janeiro (DMPI/FGEL/CTC/UERJ), apostila didática para graduação.

NASCIMENTO, M. A. L., GALINDO, A. C., e de MEDEIROS, V. C. (2015). Ediacaran to Cambrian magmatic suites in the Rio Grande do Norte domain, extreme Northeastern Borborema Province (NE of Brazil): Current knowledge. Journal of South American Earth Sciences, 58, 281-299.

NEVES, S. P.; VAUCHEZ, A.; (1995). Successive mixing and mingling of magmas in a plutonic complex of Northeast Brazil. Lithos, v. 34, n. 4, p. 275-299.

NIXON, G. T., PEARCE, T. H. (1987). Laser-interferometry study of oscillatory zoning in plagioclase; the record of magma mixing and phenocryst recycling in calcalkaline magma chambers, Iztaccihuatl Volcano, Mexico. American

Mineralogist, 72(11-12), $\quad$ 11441162.

PINHO NETO, M. A.; DA SILVA ROSA, M. L.; CONCEIÇÃO, H. (2019). Petrologia do Batólito Sítios Novos, Sistema Orogênico Sergipano, Província Borborema, NE do Brasil. Geologia USP. Série Científica, v. 19, n. 2, p. 135-150.

PITCHER, W. S. (1979). The nature, ascent and emplacement of granitic magmas. Journal of the Geological Society, v. 136, n. 6, p. 627-662. 
SÁ, J. M., GALINDO, A. C., LEGRAND, J. M., de SOUZA, L. C., MAIA, H. N. (2014). Os granitos ediacaranos no contexto dos terrenos Jaguaribeano e Rio Piranhas-Seridó no oeste do RN, Província Borborema. Estudos Geológicos, v. 24, n. 1.

SIAL, A. N. (1989). Petrologia, geoquímica de elementos maiores, traços, terras raras e isótopos (Sr, O, H, S) nos batólitos da Meruoca e Mocambo, Ceará, Nordeste do Brasil. Tese de Doutorado.

SOUZA, Z. S., MARTIN, H., PEUCAT, J. J., JARDIM DE SÁ, E. F. J., e MACEDO, M. H. D. F. (2007). Calc-alkaline magmatism at the archean-proterozoic transition: the Caicó Complex Basement (NE Brazil). Journal of Petrology, 48(11), 2149-2185.

STRECKEISEN, A.; (1976). To each plutonic rock its proper name. Earth-Science Reviews, 12, 1-33.

TETSOPGANG, S., ENAMI, M. (2003). Orthoferrosilite in a quartz monzonite from the Pan-African Belt in the Nkambe area, Cameroon. Journal of mineralogical and petrological sciences, 98(6), 235-244.
VAN SCHMUS, W.R., BRITO NEVES, B.B., WILLIAMS, I.S., HACKSPACHER, P.C., FETTER, A.H., DANTAS, E.L., BABINSKI, M. (2003). The Seridó Group of NE Brazil, a Late Neoproterozoic pre- to syncollisional flysch basin in West Gondwanaland insights from SHRIMP UePb detrital zircon ages. Precambrian Research.

VANCE, J. A. (1969). On synneusis. Contributions to Mineralogy and Petrology, v. 24, n. 1, p. 7-29.

VERNON, R. H. (1990). Crystallization and hybridism in microgranitoid enclave magmas: microstructural evidence. Journal of Geophysical Research: Solid Earth, v. 95, n. B11, p. 17849-17859.

VERNON, R.; (1991). Interpretation of microstructures of microgranitoid enclaves. I: DIDIER, J.; BARBARIN, B. (eds). Enclaves and granite petrology. Elsevier, Amsterdam, p 277-292 (Dev Petrol 13).

VERNON, R.H. (2004) A Practical Guide to Rock Microstructure. Cambridge University Press, 594 pp. 